University of Nebraska - Lincoln

DigitalCommons@University of Nebraska - Lincoln

1979

\title{
Mathematics and Mallard Management
}

Lewis M. Cowardin

USGS Northern Prairie Wildlife Research Center

Douglas H. Johnson

USGS Northern Prairie Wildlife Research Center, Douglas_H_Johnson@usgs.gov

Follow this and additional works at: https://digitalcommons.unl.edu/usgsnpwrc

Part of the Other International and Area Studies Commons

Cowardin, Lewis M. and Johnson, Douglas H., "Mathematics and Mallard Management" (1979). USGS Northern Prairie Wildlife Research Center. 212.

https://digitalcommons.unl.edu/usgsnpwrc/212

This Article is brought to you for free and open access by the US Geological Survey at DigitalCommons@University of Nebraska - Lincoln. It has been accepted for inclusion in USGS Northern Prairie Wildlife Research Center by an authorized administrator of DigitalCommons@University of Nebraska - Lincoln. 


\title{
MATHEMATICS AND MALLARD MANAGEMENT
}

LEWIS M. COWARDIN, Northern Prairie Wildlife Research Center, Jamestown, ND 58401

DOUGLAS H. JOHNSON, Northern Prairie Wildlife Research Center, Jamestown, ND 58401

\begin{abstract}
Waterfowl managers can effectively use simple population models to aid in making management decisions. We present a basic model of the change in population size as related to survival and recruitment. A management technique designed to increase survival of mallards (Anas platyrhynchos) by limiting harvest on the Chippewa National Forest, Minnesota, is used to illustrate the application of models in decision making. The analysis suggests that the management technique would be of limited effectiveness. In a 2nd example, the change in mallard population in central North Dakota is related to implementing programs to create dense nesting cover with or without supplementary predator control. The analysis suggests that large tracts of land would be required to achieve a hypothetical management objective of increasing harvest by $50 \%$ while maintaining a stable population. Less land would be required if predator reduction were used in combination with cover management, but questions about effectiveness and ecological implications of large scale predator reduction remain unresolved. The use of models as a guide to planning research responsive to the needs of management is illustrated.
\end{abstract}

J. WILDL. MANAGE. 43(1):18-35

Management of a wildlife population is a complicated task that often requires decisions based on limited data. To make logical decisions we need (1) a management policy or objective defined in terms of some goal, (2) a relationship between that goal and parameters of the population to be managed, and (3) estimates of these parameters. Such a relationship is often termed a "model," and can be either quite rudimentary and qualitative or complicated and quantitative. Inadequate information often forces us to use models that grossly oversimplify the behavior of the real population and to employ estimates that are frequently little better than informed guesses. The manager cannot postpone a decision until the dynamics of the population are fully understood and precise estimates of all parameters are available. Inaction is in fact a decision by default.

The development of simple models, imperfect though they may be, and the graphic representation of these models can facilitate logical and orderly development of management strategy. Because of the large quantity of pertinent banding and survey data available, the mallard has been the subject of several published models (Walters et al. 1974, Anderson 1975a,b, Brown et al. 1976). These models use estimates of production based on survey data for the continental population. In contrast, our model relates recruitment to various components that are frequently measured in local studies and that are subject to manipulation by the waterfowl manager. The exercise of presenting a model has a number of benefits: (1) inspection of the model may focus attention on critical parameters; (2) the model provides a frame of reference for evaluating policy and assessing the feasibility of objectives; (3) insight into possible alternatives for reaching an objective is gained; and (4) we are forced to face the reality of the management problem and to answer important questions such as cost effectiveness and political feasibility. The purpose of this paper is to demonstrate a simple model that can facilitate decisions concerning management of mallards in the north central United States.

We gratefully acknowledge the assistance of I. J. Ball, H. F. Duebbert, D. S. Gilmer, K. F. Higgins, L. M. Kirsch, A. 
D. Kruse, C. H. Schroeder, and D. L. Trauger, who permitted us to use unpublished data from their files. D. A. Davenport assisted with computer programming and preparation of graphics. We also benefited from review of the manuscript by D. R. Anderson, H. F. Duebbert, K. F. Higgins, G. S. Hochbaum, L. M. Kirsch, H. W. Miller, and A. B. Sargeant, and the editorial assistance of $\mathrm{F}$. B. Lee.

\section{THE BASIC MODEL OF SURVIVAL AND RECRUITMENT}

One purpose of management is to change the size of the population or to maintain the size while manipulating other factors such as hunting kill. The annual change in population size is a function of recruitment and survival. Because recruitment does not seem to be limited by a shortage of male mallards, we consider only the female segment of the population. For some geographically defined population, let

$$
\begin{aligned}
N_{t}= & \text { number of females in the spring } \\
& \text { of year } t, \\
S= & \text { annual survival rate of adult fe- } \\
& \text { males, } \\
S^{*}= & \text { survival rate of immature females } \\
& \text { (from fall to spring), } \\
R= & \text { number of young females in the } \\
& \text { fall population produced per } \\
& \text { adult female in the previous } \\
& \text { spring population. }
\end{aligned}
$$

The number of females the next spring is the number of adult females that survive plus the surviving young females; i.e.,

$$
N_{t+1}=N_{t} S+N_{t} R S^{*}
$$

and the proportional change in population, $C$, is

$C=N_{t+1} / N_{t}=\left(N_{t} S_{t}+N_{t} R S^{*}\right) / N_{t}=S+R S^{*}$.
To maintain a constant population we need $C=1$, which implies $R S^{*}=1-S$. This well-known result simply states that the surviving recruits $\left(R S^{*}\right)$ must balance the loss in the adult population $(1-S)$.

To describe the population dynamics of female mallards in terms of significant events occurring during the year, we split the year into periods (Fig. 1). In the following, we will take $S_{h}$ and $S_{h}{ }^{\prime}$ to represent survival from hunting. Natural mortality occurring during the hunting season will be included with winter mortality. The survival rates applicable to each period are defined in Table 1 . We assume that returning young (as yearlings) have the same recruitment rates and summer mortality rates as do adults. The assumption may be open to question, but at present there are insufficient data to warrant use of different recruitment rates for young and adults.

The survival rate, as estimated from an analysis of band recoveries, pertains to the period from the time of banding one year to the time of banding the next. Thus, for banding done just before the hunting season,

$$
S=S_{h} S_{w} S_{b}
$$

and

$$
S^{\prime}=S_{h}{ }^{\prime} S_{w}{ }^{\prime} S_{b}{ }^{\prime} .
$$

In the model for population change (equation 1), we need the survival of immatures from the fall to the next spring, which is $S^{*}=S_{h}{ }^{\prime} S_{w}{ }^{\prime}$. This quantity can be obtained by dividing the annual survival rate $S^{\prime}$ by the summer survival rate $S_{b}{ }^{\prime}$ ( $=S_{b}$ by the assumption that yearlings and adults have identical summer survival rates). Hence equation 1 becomes

$$
C=S+R S^{*}=S+R S^{\prime} / S_{b} .
$$

For a constant population $(C=1)$, equation 3 is a special case of equation 9 pre- 

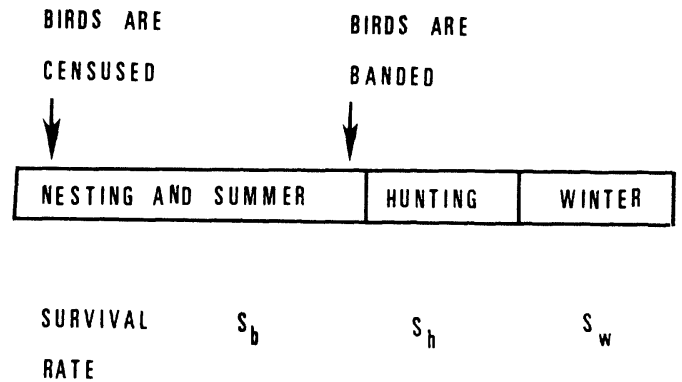

Fig. 1. Schematic drawing of a 1-year cycle showing time birds are censused, time of banding, and survival rates corresponding to each period.

sented by Henny et al. (1970). The main difference is that those authors define recruitment in terms of a single anniversary date, whereas we define recruitment as young fledged to the fall population from adults present in the spring, a definition more consistent with data gathered by waterfowl workers. Recruitment $(\bar{m})$ as defined by Henny et al. (1970) is equivalent to our $R / S_{b}$.

The ratio of survival of young to that of adults, differential survival

$$
D=S^{\prime} / S
$$

is a useful statistic (Johnson 1974) that allows further simplification of equation 3 :

$$
C=S+R D S / S_{b}=S\left(1+D R / S_{b}\right) .
$$

\section{Example: Maintaining a Constant Population}

For a stable population we can illustrate the relationship between adult survival $(S)$ and recruitment rate corrected for summer survival $\left(R / S_{b}\right)$ by graphing the function obtained by setting $C=1$ in Equation 4,

$$
S=1 /\left(1+D R / S_{b}\right)
$$

for various values of $D$ (Fig. 2).

The general form of the curves has 2 important management implications. First, the importance of a high rate of sur-
Table 1. Definitions of survival rates for various periods of the year.

\begin{tabular}{llc}
\hline & \multicolumn{2}{c}{ Notation } \\
\cline { 2 - 3 } \multicolumn{1}{c}{ Parameter } & Adult & Young \\
\hline Annual survival rate & $S$ & $S^{\prime}$ \\
$\begin{array}{l}\text { Survival during the breeding season } \\
\text { (approximately time of census to }\end{array}$ & & \\
$\quad \begin{array}{l}\text { hunting season) } \\
\text { Survival during hunting season }\end{array}$ & $S_{b}$ & $S_{b}{ }^{\prime}$ \\
$\begin{array}{l}\text { Survival during winter (end of hunt- } \\
\text { ing season to spring census) }\end{array}$ & $S_{w}$ & $S_{h}{ }^{\prime}$ \\
\hline
\end{tabular}

vival in the young relative to that in the adults $(D$ near 1$)$ is readily apparent. For example, at a fixed rate of recruitment adjusted for summer mortality, say at 1 young hen produced per adult hen in the breeding population, a species like the mallard with differential survival of around $D=0.85$ (Anderson 1975a) would require only about $54 \%$ adult survival to maintain a stable population, whereas a species like the canvasback (Aythya valisineria) with differential survival reported at about $D=0.4$ (Geis 1959) would require $70 \%$ annual survival.

Second, the form of the curves shows that when recruitment is low (less than 1 young female produced per adult female), a small change in recruitment can compensate for a relatively large change in adult survival, i.e., it will maintain a nearly constant population in the face of marked changes in survival rate. Management designed to change recruitment rate, therefore, can be expected to be an effective strategy when recruitment is modest.

\section{Example: Varying the Population Size}

The waterfowl manager is often interested in changing the population size. We can examine the relationship between recruitment and survival for various rates of population change by se- 


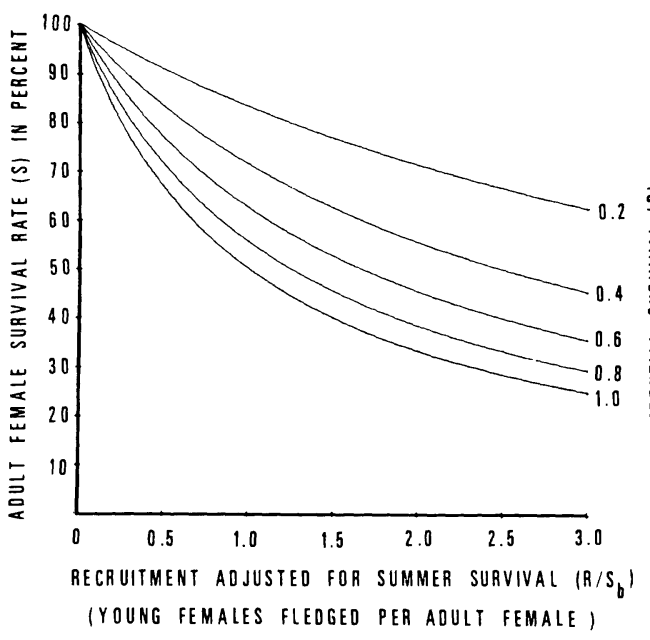

Fig. 2. Graph showing how a constant population can be maintained $(C=1)$ by various combinations of adult $f e-$ male survival rate, differential survival, and recruitment adjusted for summer survival.

lecting a fixed rate of differential survival. For the following illustration we chose $D=0.85$ (Anderson 1975a). To illustrate the relationship between recruitment and survival, we graphed (Fig. 3) the function

$$
S=C /\left(1+D R / S_{b}\right)
$$

for $D=0.85$ and for various rates of population change $(C)$. Figure 3 will be employed in the next section to estimate the annual change in populations for which estimates of $S, R$, and $S_{b}$ are available.

\section{MEASUREMENT OF SURVIVAL AND RECRUITMENT}

The manager whose objective is to manipulate the size of a wildlife population, whether he uses quantitative models or more informal methods, is aided by knowledge of survival and recruitment. Both quantities, unfortunately, are extremely difficult to determine in wild waterfowl populations. Estimation of survival is the subject of a study by Anderson $(1975 a)$, who presents survival rates

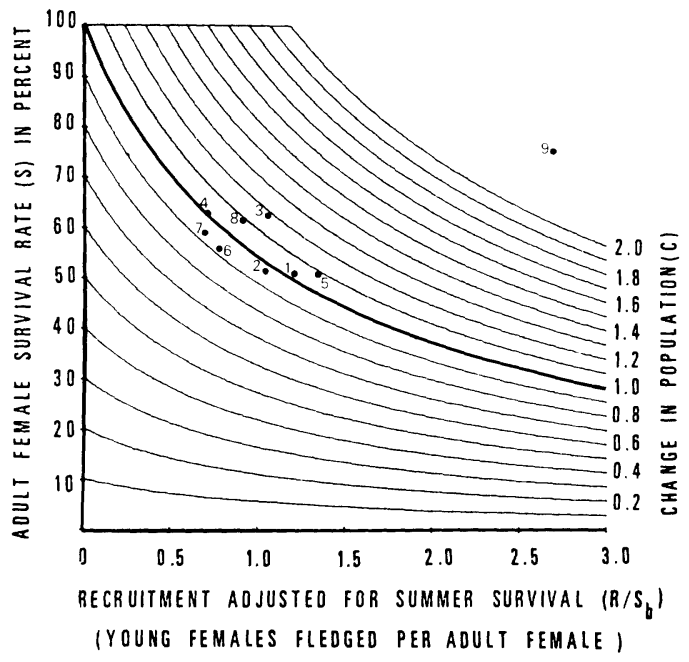

Fig. 3. Anticipated changes in population resulting from $D=0.85$ and various values of adult female survival rate and recruitment adjusted for summer survival. Plotted also are estimated values for certain study areas defined in Table 3 .

for mallards banded in various areas of North America. Estimation of recruitment has not received equal attention and the few available estimates have been derived by various methods that often are not comparable. In this section we examine the components of recruitment, present estimated survival and recruitment rates for various mallard populations, and examine the conclusions reached by incorporating these estimates in our basic model.

Recruitment can be estimated either by (1) direct measurement of breeding population, number of broods produced, and brood size, or by (2) nest success information in conjunction with knowledge of renesting effort and brood survival (Dzubin and Gollop 1972). The first method is the most straightforward, but it is difficult to determine the number of broods fledged, particularly for the secretive mallard, and estimates of recruitment can be badly biased (Stoudt 1971). The 2nd method has not often been 
Table 2. Definitions of components of recruitment and their notation.

\begin{tabular}{lc}
\hline Parameter & Notation \\
\hline $\begin{array}{l}\text { Nest success rate, the probability that an } \\
\text { individual nest will hatch }\end{array}$ & $P$ \\
$\begin{array}{l}\text { Hen success rate, the probability that an } \\
\text { individual hen will hatch a nest in } 1 \\
\text { of her attempts }\end{array}$ & $H$ \\
$\begin{array}{l}\text { Average brood size at fledging a } \\
\text { Survival of broods from hatch to time of } \\
\text { brood census }\end{array}$ & $B$ \\
$\begin{array}{c}\text { Index to recruitment }=\frac{\text { number of broods }}{\text { censused }} \\
\text { number of hens } \\
\text { censused }\end{array}$ & $I$ \\
\hline
\end{tabular}

- Size at fledging is approximately equal size at age class III (Gollop and Marshall 1954).

${ }^{b}$ Assume brood size is measured at census at early age class II.

attempted, although a number of studies (e.g., Townsend 1966, Miller 1971, Duebbert and Kantrud 1974, Reed 1975, Duebbert and Lokemoen 1976) have used nesting success as an index to recruitment. Most nesting studies yield data on the proportion of nests that hatch out of the total nests found. These estimates are usually biased because the search techniques are more likely to miss a destroyed nest than a successful nest (Miller and Johnson 1978). Mayfield (1961) recognized this bias and described a method for calculating a more realistic estimate of the probability that an individual nest will hatch. We have used Mayfield's technique as modified for waterfowl by Miller and Johnson whenever the original data were available.

The recruitment parameters are defined in Table 2; the chronology of brood development is shown in Fig. 4. Recruitment, the number of young females fledged per hen in the breeding population, is calculated by the direct method:

$$
R=I B / 2,
$$

where the divisor 2 accounts for an even sex ratio in the broods. $I$ is the ratio of

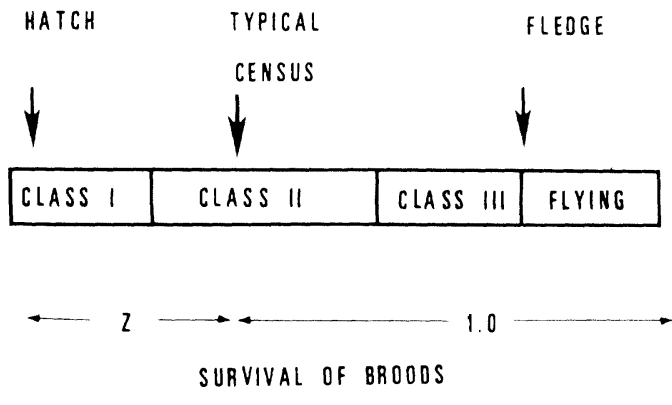

Fig. 4. Schematic drawing of stages of development of broods and the brood survival rates during each stage.

number of fledged broods to the number of pairs counted in the same area.

$B$, the average size of fledged broods, is usually assumed equal to the size of class III (approximately 51 days oldGollop and Marshall 1954) broods, which appears to be an easy parameter to measure. M. C. Hammond (unpublished report on file at Northern Prairie Wildlife Research Center) showed that class III brood sizes are subject to rather serious bias in operational surveys. Brood surveys are usually conducted in July, when any class III mallard broods encountered would be from nests hatched early in the season. Hammond and later Batt (1976) showed that early clutches are larger than late clutches and Hammond also found higher hatchability for early clutches. Published class III brood sizes, therefore, are frequently too high, and may be further inflated because of combined broods that are tallied as 1 brood. In fact, class III sizes are sometimes larger than class II sizes (e.g., Dzubin and Gollop 1972:126, Ball et al. 1975:778). Hammond constructed duckling survival curves from data gathered throughout the season at J. Clark Salyer National Wildlife Refuge in North Dakota. We calculated from his mallard data the following survival rates: hatch to class I, 0.74 ; class I to class II, 0.92; class II to class III, 0.89 . In general, estimates of class I 
brood sizes are the least biased. We therefore applied the calculated survival rates to published class I brood sizes to estimate class III brood sizes. These calculated sizes were used unless they exceeded the published sizes, in which case the latter were used.

Recruitment can alternatively be calculated from the hen success rate $(H)$ by

$$
R=H Z B / 2,
$$

although hen success is rarely measured unless marked birds are available. In addition, this method requires estimates of survival of broods from hatch to census $(Z)$, not to be confused with the attrition of broods by duckling loss, which is incorporated in the average brood size. Two recent papers (Ball et al. 1975, Reed 1975) discuss brood survival and include survival curves for broods from hatching to fledging. Inspection of the curves reveals that complete loss of broods from about 2 weeks of age to fledging is negligible. We ignored this loss and, therefore, obtained equation 5 .

Little information on the survival of broods has been published. For data from the Chippewa National Forest we used the value $Z=0.77$ derived from Ball et al. (1975). For other areas we used $Z=$ 0.70, because Dzubin and Gollop (1972) and Reed (1975) presented data suggesting that the value obtained on the Chippewa Forest is too high for a general estimate. The work of Dzubin and Gollop also suggested that brood survival may vary greatly among years and areas.

The probability of a nest hatching $(P)$, calculated according to Miller and Johnson (1978), is a parameter relatively easy to measure in grassland habitats by means of a cable chain drag (Higgins et al. 1969). The probability that an individual hen will succeed in hatching a clutch of eggs $(H)$ is a function of $P$ and the

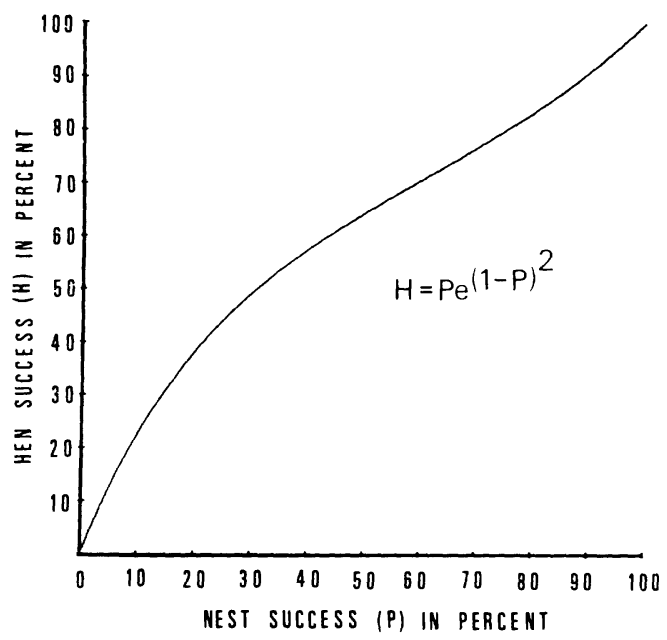

Fig. 5. Hypothesized relationship between the probability of eventual hen success and the probability that an individual nest will hatch.

number of times she will renest following destruction of her nest. Unfortunately, there are few published data on renesting rates in wild populations, data which are necessary to estimate $H$ from $P$. In Appendix 1 we argue that the relationship between $H$ and $P$ on a longterm average can be approximately described by the function:

$$
H=P e^{(1-P)^{2}},
$$

which is plotted in Fig. 5. The only study (Gilmer et al. 1974) that determined both $P$ and $H$ involved radiotelemetry data gathered on the Chippewa National Forest, Minnesota. Unpublished data obtained during this study allowed us to estimate $P=0.14$ and $H=0.28$ for a sample of 33 radio-marked mallard hens. From the estimated $P$ and our hypothesized relationship we predict $H$ to be 0.29 , which is in close agreement with the observed value. For this data set, at least, our hypothesis is reasonable. The relationship is thought to be appropriate for long-term averages; in any given year 
Table 3. Parameters for adult female mallard populations calculated for various data sets from the central portion of the breeding range. ${ }^{\mathrm{a}}$

\begin{tabular}{|c|c|c|c|c|c|c|c|c|c|c|c|c|}
\hline & Area and treatment ${ }^{\mathrm{b}}$ & Years & $P$ & $H$ & $B$ & $I$ & $R$ & $S$ & $S^{\prime}$ & $S_{b}$ & $S_{w}$ & $C$ \\
\hline 1 & $\begin{array}{l}\text { Redvers, Sask. } \\
\text { (wet years) }\end{array}$ & $52-58$ & 0.28 & 0.47 & 5.40 & 0.33 & 0.89 & $0.515^{\mathrm{c}}$ & $0.406^{\mathrm{c}}$ & $0.757^{\mathrm{d}}$ & & 0.99 \\
\hline \multicolumn{13}{|c|}{2 Redvers, Sask. } \\
\hline 3 & $\begin{array}{l}\text { Lousana, Alta. } \\
\text { Lours years) }\end{array}$ & $\begin{array}{l}59-03 \\
53-65\end{array}$ & 0.21 & $\begin{array}{l}0.46 \\
0.44\end{array}$ & $\begin{array}{l}4.81 \\
5.10\end{array}$ & 0.32 & $\begin{array}{l}0.18 \\
0.79\end{array}$ & $\begin{array}{l}0.515 \\
0.623\end{array}$ & $\begin{array}{l}0.406 \\
0.482\end{array}$ & $\begin{array}{l}0.754 \\
0.748\end{array}$ & & $\begin{array}{l}0.94 \\
1.13\end{array}$ \\
\hline 4 & Kindersley, Sask. & $56-59$ & 0.14 & 0.30 & 4.91 & 0.21 & 0.52 & 0.623 & 0.482 & 0.719 & & 0.96 \\
\hline 5 & Roseneath, Man. & $52-55$ & 0.39 & 0.57 & 5.17 & 0.40 & 1.03 & 0.515 & 0.406 & 0.786 & & 1.04 \\
\hline 6 & Chippewa Forest, Minn. & $68-72$ & 0.14 & 0.28 & 5.40 & 0.22 & 0.59 & 0.559 & 0.475 & 0.750 & 0.919 & 0.93 \\
\hline 7 & N. Dak. (unmanaged) & $69-75$ & 0.14 & 0.29 & 4.90 & 0.20 & 0.50 & 0.587 & 0.555 & 0.719 & 0.918 & 0.98 \\
\hline 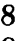 & N. and S. Dak. (DNC) & $71-73$ & 0.21 & 0.39 & 4.90 & 0.27 & 0.67 & 0.601 & 0.568 & 0.738 & 0.918 & 1.12 \\
\hline \multirow{2}{*}{\multicolumn{13}{|c|}{9 Hosmer, S. Dak. (DNC }} \\
\hline & & 71 & 0.87 & 0.88 & 6.44 & 0.75 & 2.41 & 0.751 & 0.710 & 0.914 & 0.918 & 2.63 \\
\hline
\end{tabular}

a Data for parameters for which real data were available are italicized. Other parameters were developed from the assumptions and equations discussed in the text. All estimates are subject to large sampling errors and are intended only to illustrate the models.

bource data were taken from the following publications: 1 and 2 (Stoudt 1971), 3 (Smith 1971), 4 and 5 (Dzubin and Gollop 1972). Sources of previously unpublished data for areas 6-9 are cited in the appendix.

c Survival estimates except for Minnesota are taken from Anderson (1975a). The reference area with large samples of banded birds nearest the study ares was used. Estimates for Minnesota were derived from banding data for the entire state.

d Survival estimates derived from equation A5.

renesting effort may be near zero because of climatic conditions and the equation could yield highly misleading results.

We may now use the estimates of recruitment from various studies to determine the status of the populations studied, and later to examine management strategies. If we combine the formula for change in population (equation 4) with those for recruitment and hen success (equations 5 and 6), we can write a single equation relating the parameters discussed thus far:

$$
C=S\left(1+1 / 2 D P e^{(1-P)^{2}} Z B / S_{b}\right) .
$$

As a further check on our assumptions, we examined results from a number of studies in which different parameters were measured, and then calculated the additional parameters needed to determine recruitment. We also derived estimates for the various components of survival. The estimates were used in equation 7 to predict the average $C$ for each study (Table 3, Fig. 3). Note that changes in population $(C)$ estimated from the graph differ slightly from the values in Table 3 because a common value $D=$ 0.85 was used in constructing the curves, whereas values specific to the areas were used in Table 3. Estimates of $C$ for most study areas tend to fall either slightly above or slightly below the line representing no change. The most striking departure is for Hosmer, South Dakota, where a dramatic increase in population was observed during the years of high recruitment. The results are sufficiently reasonable to allow use of our model in preliminary examination of management strategies presented next.

\section{A STRATEGY TO INCREASE SURVIVAL-CHIPPEWA NATIONAL FOREST, MINNESOTA}

Data from the Chippewa National Forest furnish an example of how a simple model may facilitate critical examination of a proposed management strategy. We have shown (Table 3 , area 6 ) that if our estimated rates of recruitment $\left(R / S_{b}=\right.$ $0.59 / 0.75=0.79)$ and survival $(S=0.559)$ are reasonably accurate, the mallard pop- 
Table 4. Population parameters for female mallards banded on the Chippewa National Forest, Minnesota.

\begin{tabular}{|c|c|c|c|}
\hline Parameter & Notation & Value & Source \\
\hline$\%$ of nests hatched & $P$ & 0.14 & Unpublished data \\
\hline$\%$ of hens hatching a nest & $H$ & 0.28 & Gilmer et al. (1977) \\
\hline Average class III brood size & $B$ & 5.4 & (Unpublished data) I. J. Ball \\
\hline Brood survival to census & $\mathrm{Z}$ & 0.77 & Calculated from Ball et al. (1975) \\
\hline $\begin{array}{l}\text { Recruitment }=\text { young hens } \\
\text { fledged/adult hen }\end{array}$ & $R$ & 0.59 & Calculated $(0.28 \times 0.77 \times 5.4) / 2$ \\
\hline Adult survival rate & $S$ & 0.559 & Banding data state of Minnesota \\
\hline Young survival rate & $S^{\prime}$ & 0.475 & Banding data state of Minnesota \\
\hline Adult summer survival & $S_{b}$ & 0.75 & Gilmer et al. (1974) \\
\hline Adult survival from hunting & $S_{h}$ & 0.811 & $\begin{array}{l}\text { Anderson }(1975 a) \text {; crippling loss from } \\
\text { Johnson and Sargeant (1977) }\end{array}$ \\
\hline Young survival from hunting & $S_{h}{ }^{\prime}$ & 0.689 & $\begin{array}{l}\text { Anderson }(1975 a) \text {; crippling loss from } \\
\text { Johnson and Sargeant (1977) }\end{array}$ \\
\hline Adult winter survival & $S_{w}$ & 0.919 & Calculated $(0.559 / 0.811 \times 0.75)$ \\
\hline Young winter survival & $S_{w}^{\prime}$ & 0.838 & $\begin{array}{l}\text { Winter mortality assumed twice adult } \\
\text { rate }\end{array}$ \\
\hline $\begin{array}{l}\text { Proportion of harvested adults taken on } \\
\text { Chippewa Forest }\end{array}$ & $\phi$ & 0.548 & Banding data Chippewa Forest \\
\hline $\begin{array}{l}\text { Proportion of harvested young taken on } \\
\text { Chippewa Forest }\end{array}$ & $\phi^{\prime}$ & 0.424 & Banding data Chippewa Forest \\
\hline
\end{tabular}

ulation on the Forest is either declining or being maintained by pioneering birds. Jessen (1970) reached a similar conclusion for mallards throughout Minnesota.

Reference to Fig. 3 suggests the possible management strategies to achieve a stable population without immigration. We must raise adult survival rate to about $60 \%$, or raise recruitment (adjusted for summer mortality) above 0.9 , or achieve some combination of these. If hunting and natural mortality are additive (cf. Anderson and Burnham 1976), we should be able to increase survival by decreasing hunting mortality. The fact that, of all direct recoveries of adults banded on the Chippewa National Forest, $55 \%$ were recovered on the Forest suggests that restrictive regulations on the Forest might be used to increase the adult survival rate. In fact, closure of selected areas on the Forest to duck hunting was examined as a potential management technique by the Minnesota Department of Natural Resources in 1972, but was never implemented.
We examined the strategy of partial closure of the Forest to duck hunting by adapting our basic model to determine the percentage change in the population as a function of the percentage of the harvest taken on the Forest, for various rates of recruitment. Details of the model specific to this example are found in Appendix 2. If we assume that harvest rates elsewhere than the Forest would be unchanged by local closure and apply the current data from the Forest (Table 4) to the graph (Fig. 6), we predict about a 7\% annual decline in population, as we did in Table 3. The percentage of kill taken on the Chippewa National Forest would have to be reduced from about 55 to $30 \%$ in order to obtain a stable population without immigration. With complete closure of the Forest we would attain a modest rate of increase, about $4 \%$ per year. From the form of the curves (Fig. 6) it is apparent that there is little change in population when the percentage kill on the Forest varies in the range of 0 to 60 . The reason for this is that birds not suc- 


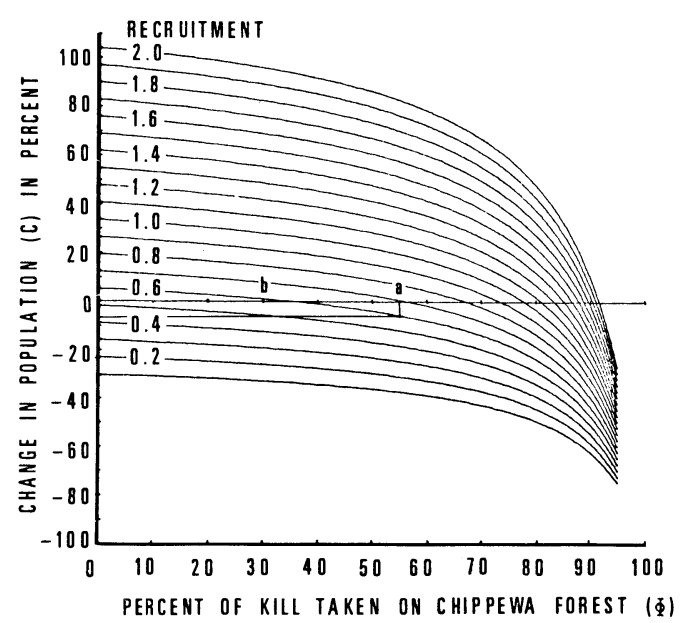

Fig. 6. Relationship between percentage of the total harvest taken on the Chippewa National Forest Minnesota $(\phi)$ and change in population (C) for various levels of recruitment $(R)$. a denotes observed value of $\phi$. b denotes allowable values of $\phi$ for stable population.

cumbing on the Forest still suffer rather heavy hunting mortality elsewhere.

\section{A STRATEGY TO INCREASE RECRUITMENT-EASTERN NORTH DAKOTA}

Many studies (e.g., Benson 1964, Gates 1965, Balser et al. 1968, Miller 1971, Duebbert and Kantrud 1974, Duebbert and Lokemoen 1976) have demonstrated that waterfowl hatching success varies according to height and density of nesting cover and/or the reduction of predators. These studies suggest that creation of dense nesting cover, possibly combined with predator control, might be an effective technique for increasing recruitment among dabbling ducks in the glaciated prairie of the United States. $H$. K. Nelson (unpublished paper presented to the Migratory Bird Commission, Washington, D.C., 22 January 1974) reviewed the findings to date and outlined a program for establishing 320 to 400 ha of high quality nesting cover per township in prime waterfowl habitat of the Dako- tas. A study to assess the results of a pilot program is underway.

Although the latter study will not be completed for some time, we illustrate how modeling might aid a decision on cover management. A number of the estimates that we use in the models are preliminary and will be improved in the future, but this situation is typical of that faced each day by managers, who must make decisions even when data are lacking or inadequate. The problem furnishes a good example of the advantages of models.

We adapted our basic model (equation 7) to predict the population change that would result if a certain percentage of the mallard hens in North Dakota nested in managed cover. The 2 treatments considered were dense nesting cover (DNC) and DNC with predator control. For estimates of recruitment in unmanaged North Dakota cover we used to the data of Higgins (1977), combined with data gathered by A. D. Kruse on representative tracts of untreated land in eastern North Dakota, and data obtained by L. M. Kirsch from unmanaged pastures near Woodworth, North Dakota. The nests in these data sets were located primarily in uplands. Mixed upland and overwater nesting was also considered by incorporating into the data set above some unpublished information gathered by G. L. Krapu on overwater nests. Recruitment on lands with DNC was estimated from the original data used by Duebbert and Lokemoen (1976) and data gathered by L. M. Kirsch near Woodworth, North Dakota, on fields that he felt were of optimum cover quality. For recruitment on an area with both DNC and predator control we used data from the best single year (1971) at Hosmer, South Dakota (Duebbert and Kantrud 1974). Our estimates of $P$ for these 3 situations are in- 


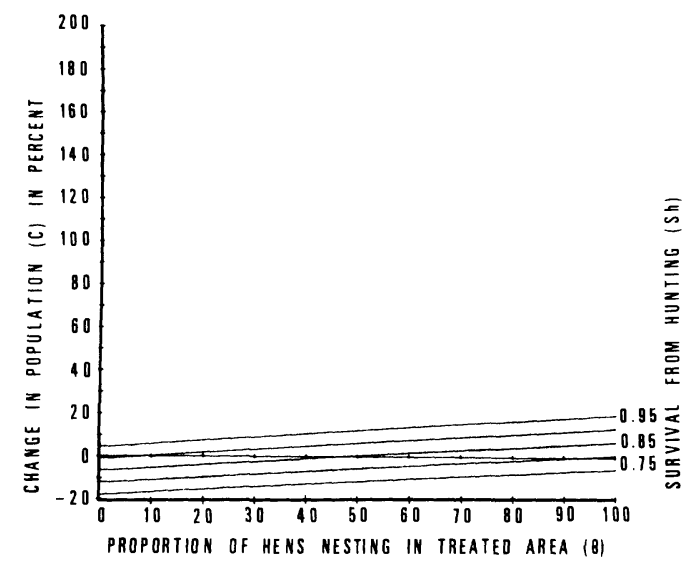

Fig. 7. Relationship between annual change in population and proportion of hens nesting in dense nesting cover.

cluded in Table 3 (areas 7, 8, and 9). Details of the model specific to the 2 treatments are provided in Appendix 3.

The analysis suggests that mallard populations nesting in unmanaged uplands in North Dakota should be decreasing slightly, at an average annual rate of about $2 \%$ (Table 3 , area 7 ). If we include data from overwater nests, the hatch rate becomes $P=0.21$, the same as in DNC (Table 3, area 8). If mallards were nesting in upland and overwater situations in the same proportion as in our sample of nests, the population would be increasing about $12 \%$ annually. Such an increase seems unlikely, and we do not yet know the frequency of overwater nesting, so we consider the upland nests to be representative of the unmanaged situation in North Dakota. If further research indicates that a substantial percentage of mallards do nest overwater, and that the hatch rate is appreciably different from upland nests, then our conclusions about the unmanaged situation would be voided.

Graphs illustrating the change resulting from the 2 treatments are given in

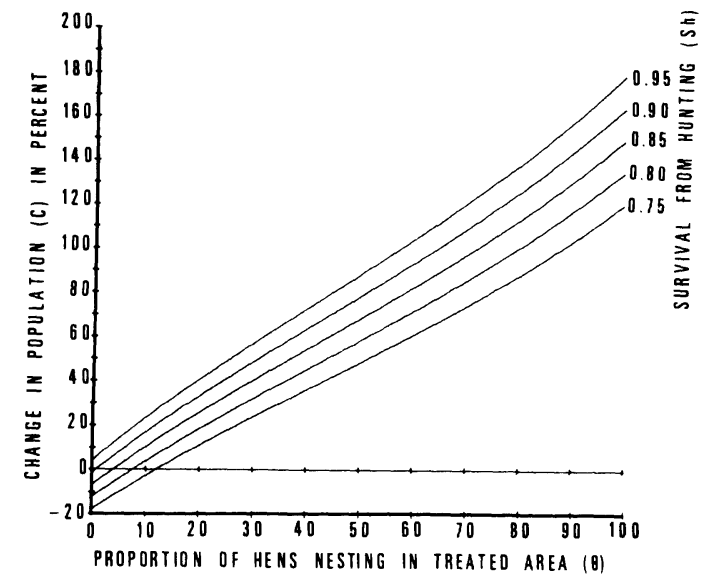

Fig. 8. Relationship between annual change in population and proportion of hens nesting in dense nesting cover with predator control.

Figs. 7 and 8. Each shows the population change anticipated at a fixed rate of survival from hunting. The relationship for DNC alone (Fig. 7) indicates that the population change $C$ is nearly linear in $\theta$, the proportion of hens nesting in treated cover. The slope of the curve is slight, because the increase in $P$ due to the treatment is rather modest (Table 3 ). In contrast, the anticipated population change varies markedly with the percentage of birds nesting in DNC plus predator control (Fig. 8).

We may now examine some management alternatives: planting DNC, planting DNC and controlling predators, and leaving the land unmanaged. Suppose we wish to maintain a stable population while increasing the kill rate to $15 \%, S_{h}=$ 0.85 . This change may appear minor but actually represents nearly a $50 \%$ increase in the harvest. To achieve this objective, our model suggests that we would need to place about $50 \%$ of the hens in dense nesting cover (Fig. 7) or $4 \%$ in the cover with supplementary predator control (Fig. 8).

It is possible to carry these arguments 
Table 5. Area required under 2 management techniques to achieve an objective of $15 \%$ kill rate and stable population for mallards in eastern North Dakota.

\begin{tabular}{|c|c|c|c|c|}
\hline Treatment & $\begin{array}{l}\text { Hens required in } \\
\text { treated area }\end{array}$ & Nests/hen & Hens $/ \mathbf{k m}^{2}$ & $\begin{array}{c}\text { Area needed } \\
\left(\mathrm{km}^{2}\right)^{\mathrm{b}}\end{array}$ \\
\hline Dense nesting cover & 89,100 & 1.79 & 80 & 1,114 \\
\hline Dense nesting cover and predator control & 7,128 & 1.02 & 141 & 51 \\
\hline
\end{tabular}

- Equals $H / P$ in Table 3.

B Based on nest density of 144 nests $/ \mathrm{km}^{2}$.

1 step further and estimate the amount of land necessary to accomplish the management objective. For this estimate, we need the number of nests supported per unit of habitat. Because the maximum attainable density of nesting mallards is not known, we used the high density 132 nests $/ \mathrm{km}^{2} \quad$ (= 299 nests $/ \mathrm{km}^{2} \times 44 \% \mathrm{mal}-$ lards) observed by Duebbert and Kantrud (1974). Observed nest density is biased low (Miller and Johnson 1978) but can be adjusted by Mayfield's (1961) method, which yields an estimate of 144 nests $/ \mathrm{km}^{2}$.

Pospahala et al. (1974) gave an average spring population estimate of 387,400 mallards for eastern North Dakota. This population would include 178,200 hens if we use a spring sex ratio of 118:100 (Johnson and Sargeant 1977). From these data we can estimate the area required to reach the management objective ( $\mathrm{Ta}$ ble 5).

H. K. Nelson suggested a target figure of $320-400$ ha of high quality nesting cover per township. Eastern North Dakota (reference area 131 as defined by Pospahala et al. 1974) is approximately 128,300 $\mathrm{km}^{2}$ in size so Nelson's target is equivalent to $4,500-5,600 \mathrm{~km}^{2}$. Our analysis suggests (Table 5) that this figure would be more than adequate to achieve our hypothetical management objective.

\section{RESEARCH IMPLICATIONS}

Even such a rudimentary model as that presented in equation 7 has certain merit in planning research because it permits a logical and integrated rather than haphazard approach to a problem. We assessed the relative importance of the parameters in equation 7 by determining how sensitive the model was to changes in each of them. The analysis suggested that survival $(S)$, nest success $(P)$, and the number of renests attempted by a hen $(H /$ $P$-incorporated in the assumptions of equation 6) are the most crucial parameters.

One needs only to review the standard errors of survival estimates for individual years to realize that additional effort is needed to develop more precise estimates and to avoid possible biases associated with unbanded populations (Anderson 1975a). Anderson and Burnham (1976) suggested that natural mortality compensates for hunting mortality up to some unknown threshold, where they become additive. If management is to change survival through regulation of harvest, a hypothesis that we are not yet willing to abandon, the theory suggested by Anderson and Burnham must be fully understood, particularly the mechanisms by which natural mortality compensates for hunting mortality and the threshold level of hunting mortality below which this occurs.

Although considerable research effort has been devoted to estimation of the probability that a nest hatches $(P)$, little is known about renesting and the environmental factors that affect it. These fac- 
tors must be better understood if reasonable recruitment rates are to be derived from nest success data. By use of radiotelemetry or visual markers, direct measurement of hen success $(H)$ is sometimes possible. Unfortunately there are few published studies where this attempt has been made. Although not as crucial as survival of adults, nest success, and hen success, the measurement of brood survival $(Z)$ is essential for calculating recruitment $(R)$ from nesting data. This parameter is not only poorly known, but also its relationship to habitat condition has received little attention. Class III brood size $(B)$, necessary to calculate recruitment, is usually biased by late broods being underrepresented in the sample.

To be responsive to the needs of management, research must concentrate on those parameters of the model that are not only important, but can reasonably be measured in operational surveys. If an important parameter is difficult to measure, it may be possible to find a relationship between that parameter and one that is easy to measure, and thus to estimate 1 parameter from the other. For example, the renesting rate, which is difficult to measure, may well be correlated with availability of wetland habitat during the nesting season. It could, therefore, be possible to determine renesting from measurements of habitat. A similar approach may be possible for estimating brood survival $(Z)$, which is probably a function of the distance from nest to water and among water areas used by a brood.

A balanced waterfowl research effort, therefore, requires long-term accurate surveys to gather information in a systematic fashion, and long-term basic ecological studies. When these latter studies are viewed in the light of a population mod- el, their application readily becomes apparent. As results become available, they may be incorporated into the model, which should evolve toward a better representation of the true behavior of the population.

\section{LIMITATIONS IN THE USE OF MODELS}

All models that describe complex biological processes such as population dynamics are oversimplifications based on specific sets of assumptions. To use models in making decisions, the manager must be aware of the implications of underlying assumptions and the validity of parameter estimates used in the model. Models need not be highly complex to be useful; on the contrary, the simplest models are frequently the most useful.

Some assumptions of our model may be open to question, but we contend that its use will not lead to erroneous conclusions. In both of our examples of the applications of the model to specific management problems, we have assumed that hunting and natural mortality are additive. Should that not be true, the effect would be to make the conclusions reached in our examples conservative. We concluded that closure on the Chippewa Forest would not be a particularly effective management technique to increase the local breeding population. If hunting and natural mortality are even partly compensatory, the closure would be even less effective. In the 2 nd example the number of hens required in the managed area would be fewer than under the assumption of additivity, if increased harvest was at least partially offset by lower natural mortality.

When we modified our model to describe the effect of closure in part of the Chippewa National Forest, we assumed that survival from hunting elsewhere is 
not affected by survival from hunting on the Chippewa. This assumption is reasonable because even if all birds survive hunting on the Chippewa Forest, the number added to more southern harvest areas would have little effect on the total number of birds available to hunters. If closure were contemplated for a much larger area, such as a group of states and provinces on the breeding ground, the additional birds available to the southern harvest areas might influence harvest rates there. Our model would then be inadequate.

The parameter estimates that we used are subject to a number of biases discussed earlier. They also represent average conditions and are subject to large variation in both time and space. In addition, our recruitment estimates for land with DNC and for unmanaged areas in North Dakota were not obtained from a random sample of these lands and could be in error because nest success is highly variable from area to area. We presented data from fields where good quality cover was achieved by the land treatment. This success has not occurred on all lands where the cover was planted. Our recruitment estimate for the Chippewa National Forest is based on a small sample of birds obtained in 1 area of the Forest. Our current understanding of the variation associated with parameters of recruitment is insufficient to attempt to account for it in the model. By viewing a family of curves (Figs. 3, 6, 7, and 8), it is possible to assess the results of various ranges of parameter values. The fact that the results are reasonable (Fig. 3) lends some credence to the validity of the model. Despite the problem of uncertainty about assumptions and estimates, techniques presented here represent a logical way of reaching a decision based on limited information.
The manager also requires management policy and here the model cannot help. We chose real examples of problems in waterfowl management to illustrate this report. The examples demonstrate that policy and practical considerations temper the results obtained from the model.

In the 1st example our model suggests that an attempt to increase survival on the Chippewa National Forest through partial or complete closure of the Forest to hunting is of limited biological effectiveness. In our opinion, area closure on the breeding ground imposes restrictions on 1 hunter without affecting another. The individual who has invested in a hunting area and finds it closed while his neighbor's area remains open will ask, "Why me?" Such regulations also tend to penalize hunters on production areas, thus undermining local support for programs of habitat preservation.

Our 2nd example poses both practical and policy questions. If cover manipulation is used alone, large amounts of land would be required to achieve the management objective. While a thorough cost/benefit analysis is beyond the scope of this paper, it must be recognized that land most suitable for treatment is retired cropland, exclusive of native grassland and wetland areas. Excellent nesting cover may be provided on a temporary basis by various agricultural land retirement programs, at little or no cost to wildlife agencies. Without such programs, or if permanent cover is sought, wildlife agencies must purchase or rent private land, a costly alternative.

Our analysis indicates that predator control combined with cover management is more effective for increasing recruitment than cover management alone. Again, the cost effectiveness of such a program is unknown. Furthermore, pre- 
dicting results of a broad-scale predator reduction program is risky and involves many variables for which we have little data. Our results should be viewed with extreme caution because of many factors that may inhibit the effectiveness of predator control. More importantly, we believe that there are questions as to the ecological advisability of direct control of predators in order to benefit game species. Our analysis suggests that control of predators would be effective, but the manager also requires a clearly stated policy based on the legal, economic, political, and ecological implications of such a program. Methods of predator exclusion other than direct control, should be sought because they could achieve increased waterfowl recruitment without adverse side effects.

The manager must bear certain natural phenomena in mind when evaluating techniques such as those discussed in our 2nd example. The techniques primarily alter only 1 part $(P)$ of a complex relationship. Climate will continue to have an overriding influence on recruitment by altering nesting effort and brood size. We cannot control climate, which will continue to fluctuate in the northern prairies. Therefore, waterfowl populations will continue to fluctuate regardless of management. The manager can manage the land under his control, but this land represents only a fraction of the total area used by waterfowl. Fluctuation in population size is closely tied to available wetland habitat. If this base is lost, waterfowl will face permanent drought conditions and waterfowl hunters will face permanent drought-level populations.

\section{LITERATURE CITED}

ANDERSON, D. R. 1975a. Population ecology of the mallard. V. Temporal and geographic estimates of survival, recovery, and harvest rates. U.S. Fish Wildl. Serv. Resour. Publ. 125. 110pp.

- 1975b. Optimal exploitation strategies for an animal population in a Markovian environment: a theory and an example. Ecology 56:1281-1297.

- AND K. P. Burnham. 1976. Population ecology of the mallard. VI. The effect of exploitation on survival. U.S. Fish Wildl. Serv. Resour. Publ. 128. 66pp.

Ball, I. J., D. S. Gilmer, L. M. Cowardin, AND J. H. RuechmanN. 1975. Survival of wood duck and mallard broods in north-central Minnesota. J. Wildl. Manage. 39:776-780.

Balser, D. S., H. H. Dill, and H. K. Nelson. 1968. Effect of predator reduction on waterfowl nesting success. J. Wildl. Manage. 32:669682.

BATT, B. D. 1976. Reproductive parameters of mallards in relation to age, captivity, and geographic origin. Ph.D. Thesis. Michigan State Univ., Lansing. 50pp.

BENSON, R. I. 1964. A study of duck nesting and production as related to land use in Pope County, Minnesota. Pages 107-126 in J. B. Moyle, ed. Ducks and land use in Minnesota. Minn. Dep. Conserv. Tech. Bull. 8.

Brown, G. M., JR., J. HAmmack, AND M. F. TILLMAN. 1976. Mallard population dynamics and management models. J. Wildl. Manage. 40:542555.

Duebbert, H. F., AND H. A. Kantrud. 1974. Upland duck nesting related to land use and predator reduction. J. Wildl. Manage. 38:257-265. -, AND J. T. LOKEMOEN. 1976. Duck nesting in fields of undisturbed grass-legume cover. J. Wildl. Manage. 40:39-49.

DzuBIN, A., AND J. B. Gollop. 1972. Aspects of mallard breeding ecology in Canadian parkland and grassland. Pages 113-152 in Population ecology of migratory birds. U.S. Fish Wildl. Serv. Res. Rep. 2.

GateS, J. M. 1965. Duck nesting and production on Wisconsin farmlands. J. Wildl. Manage. 29:515-523.

GEIS, A. D. 1959. Annual and shooting mortality estimates for the canvasback. J. Wildl. Manage. 23:253-261.

Gilmer, D. S., I. J. Ball, L. M. Cowardin, and J. H. RiechmanN. 1974. Effects of radio packages on wild ducks. J. Wildl. Manage. 38:243252.

- R. E. KIRBY, I. J. BALL, AND J. H. RIECHMANN. 1977. Post-breeding activities of mallards and wood ducks in north-central Minnesota. J. Wildl. Manage. 41:345-359.

Gollop, J. B., and W. H. Marshall. 1954. A guide for aging duck broods in the field. Miss. Flyway Council Tech. Sect. 14pp. (Mimeo.)

Henny, C. J., W. S. Overton, and H. M. Wight. 1970. Determining parameters for populations 
by using structural models. J. Wildl. Manage. 34:690-706.

HiggiNs, K. F. 1977. Duck nesting in intensively farmed areas of North Dakota. J. Wildl. Manage. 41:232-242.

- L. M. KIRSCH, AND I. J. BALL, JR. 1969. A cable-chain device for locating duck nests. J. Wildl. Manage. 33:1009-1011.

JESSEN, R. L. 1970. Mallard population trends and hunting losses in Minnesota. J. Wildl. Manage. 34:93-104.

JoHNSON, D. H. 1974. Estimating survival rates from banding of adult and juvenile birds. J. Wildl. Manage. 38:290-297.

$\longrightarrow$, AND A. B. SARGEANT. 1977. Impact of red fox predation on the sex ratio of prairie mallards. U.S. Fish Wildl. Serv. Wildl. Res. Rep. 6. $56 \mathrm{pp}$.

MAYFIELD, H. 1961. Nesting success calculated from exposure. Wilson Bull. 73:255-261.

MILLER, H. W. 1971. Relationships of duck nesting success to land use in North and South Dakota. Trans. Congr. Int. Union Game Biol. 10:133141.

$\longrightarrow$, AND D. H. JOHNSON. Interpreting the results of nesting studies. J. Wildl. Manage. 42: $471-476$.

Pospahala, R. S., D. R. ANDERSon, AND C. J. HenNY. 1974. Population ecology of the mallard. II. Breeding habitat conditions, size of breeding populations, and production indices. U.S. Fish Wildl. Serv. Resour. Publ. 115. 73pp.

REED, A. 1975. Reproductive output of black ducks in the St. Lawrence estuary. J. Wildl. Manage. 39:243-255.

SMITH, A. G. 1971. Ecological factors affecting waterfowl production in the Alberta parklands. U.S. Fish Wildl. Serv. Resour. Publ. 98. 49pp.

STOUDT, J. H. 1971. Ecological factors affecting waterfowl production in the Saskatchewan parklands. U.S. Fish Wildl. Serv. Resour. Publ. 99. $58 \mathrm{pp}$.

TOWNSEND, G. H. 1966. A study of waterfowl nesting on the Saskatchewan River Delta. Can. Field-Nat. 80:74-88.

Walters, C. J., R. Hilborn, E. Oguss, R. M. PeTERSON, AND J. M. STANDER. 1974. Development of a simulation model of mallard duck populations. Can. Wildl. Serv. Occas. Pap. 20. $35 \mathrm{pp}$.

\section{APPENDIX 1. A RELATIONSHIP BETWEEN HEN SUCCESS AND NEST SUCCESS}

Assume the nesting effort of a hen follows the flow chart shown in Fig. 9. At the beginning of the nesting season, the hen can either attempt a nest (with prob-

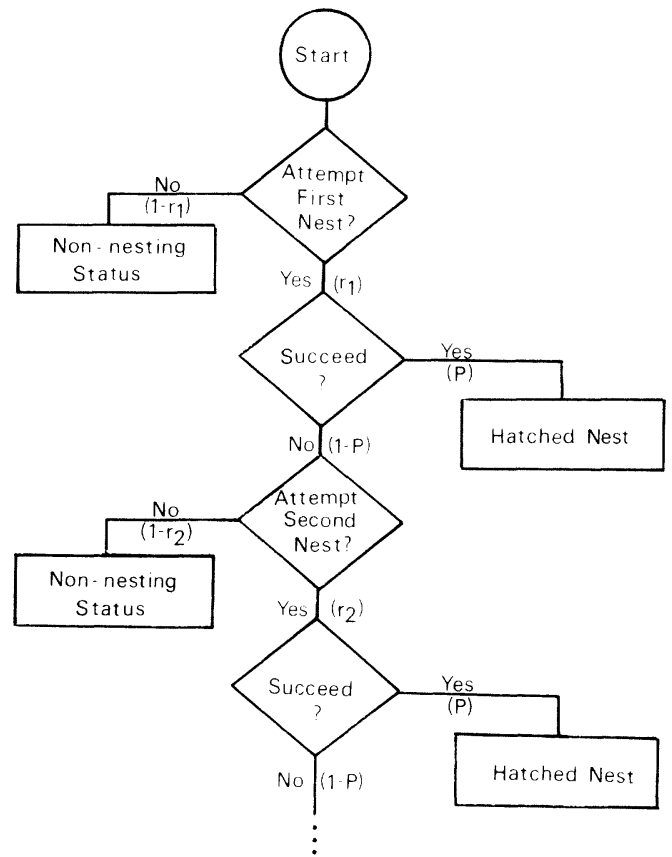

Fig. 9. Flow diagram representing nesting attempts and success of hypothetical mallard hen. Probabilities of events are shown in parentheses.

ability $r_{1}$ ) or not (with probability $1-r_{1}$ ). The nest will either hatch (with probability $P$ ) or not (with probability $1-P$ ). Should the first nest fail, the hen can attempt a 2nd nest (with probability $r_{2}$ ) or not do so (with probability $1-r_{2}$ ). That nest will either hatch (with probability $P$ ) or fail (with probability $1-P$ ). And so forth. We assume that this process continues indefinitely, although the number of nesting attempts is certainly limited. We show later that this assumption, which simplifies the mathematics, is otherwise inconsequential.

Letting

$$
\begin{aligned}
r_{i}= & \text { Prob }\left\{\text { hen attempts } i^{\text {th }}\right. \text { nest } \\
& \text { given that previous nest fail }\}
\end{aligned}
$$

and

$$
P=\operatorname{Prob}\left\{i^{\text {th }} \text { nest hatches }\right\},
$$

we find that $H$, the probability that a hen 
will hatch a nest in 1 of her attempts, is the sum of the probabilities of outcomes on the right of Fig. 9, viz.

$$
\begin{aligned}
H= & r_{1} P+r_{1}(1-P) r_{2} P \\
& +r_{1}(1-P) r_{2}(1-P) r_{3} P \\
& +\cdots+P(1-P)^{n-1} r_{1} r_{2} \cdots r_{n}+\cdots \\
= & P \sum_{i=1}^{\infty}\left[(1-P)^{i-1} \prod_{j=1}^{i} r_{j}\right] .
\end{aligned}
$$

The parameter $P$ is estimable from nesting studies. Little definitive knowledge is available about the rates of nesting, $r_{1}, r_{2}, \cdots$, but a certain structure to the rates is apparent. First, because nesting effort generally decreases as the breeding season progresses, it is reasonable to assume that $r_{i}$ decreases with increasing $i$; that is, a hen is more likely to attempt an $i^{\text {th }}$ nest than an $(i+1)$ st nest. And $\lim r_{i}=0$; the probability of a large number of nesting attempts is arbitrarily small.

Further, $r_{i}$ varies inversely with the nest success rate $P$. If $P$ is high, for example, a nest is likely to be destroyed later in laying or during incubation, and the hen is less likely to renest. Conversely, if $P$ is low, destruction is more likely to occur earlier during laying, and renesting is more likely.

A system that meets the criteria described above is given by

$$
r_{1}=\alpha
$$

and

$$
r_{i}=\alpha(1-P) /(i-1) \quad i>1 .
$$

Here $\alpha(0 \leqslant \alpha \leqslant 1)$ is an index to the overall nesting intensity. In years of normal habitat conditions, $\alpha$ will be nearly 1 ; in very dry years $\alpha$ will be lower.

Incorporating this system into equation Al, we find that
Table 6. Contributions to the series in equation A1 provided by successive terms.

\begin{tabular}{crc}
\hline$i$ & $i^{\text {th }}$ term & Sum of first $i$ terms \\
\hline 1 & 0.140 & 0.140 \\
2 & 0.104 & 0.244 \\
3 & 0.038 & 0.282 \\
4 & 0.009 & 0.291 \\
5 & 0.002 & 0.293 \\
$\infty$ & 0 & 0.293 \\
\hline
\end{tabular}

$$
\begin{aligned}
H & =P \sum_{i=1}^{\infty}(1-P)^{i-1} \alpha^{i}(1-P)^{i-1 /(i-1) !} \\
& =\alpha P \sum_{i=1}^{\infty}\left[\alpha(1-P)^{2}\right]^{i-1 /(i-1) !}
\end{aligned}
$$

The summation may be recognized as the power series expansion for $\exp [\alpha(1-$ $P)^{2}$ ]. Therefore

$$
H=\alpha P \mathrm{e}^{\alpha(1-P)^{2}} .
$$

We use this relationship with $\alpha=1$ for determining $H$ from $P$. It is plotted in Fig. 5.

Although we allowed in equation Al for an infinite number of nesting attempts, this is precluded by the nature of the rates $\left(r_{i}\right)$. Table 6 shows for the Chippewa National Forest example where $P=$ 0.14 that, to 3 significant digits, the first 5 terms of the series determine $H$. That is, we would get the same answer allowing only 5 nesting attempts as allowing an infinite number.

\section{APPENDIX 2. PARAMETERS SPECIFIC TO THE CHIPPEWA NATIONAL FOREST EXAMPLE}

It was necessary to subdivide survival from hunting into temporal components corresponding to the areas where hunting occurred

$$
S_{h}=S_{c} S_{e}
$$


where

$S_{h}=$ survival from hunting, as before,

$S_{c}=$ survival from hunting on the Chippewa National Forest,

$S_{e}=$ survival from hunting elsewhere.

The corresponding equation for young is

$$
S_{h}{ }^{\prime}=S_{c}{ }^{\prime} S_{e}{ }^{\prime} \text {. }
$$

We assume that $S_{c}$ and $S_{e}$ are independent; that is, the rate of kill elsewhere will not vary just because the kill rate on the Forest changes, although both rates are affected by federally prescribed hunting regulations.

From banding data (Table 4) the hunting survival rates are $S_{h}=0.811$ and $S_{h}{ }^{\prime}=$ 0.689 ; the fraction of hunter-shot birds that are taken on the Forest is $54.8 \%$ among adults and $42.4 \%$ among juveniles. The proportion of the fall population shot on the Forest is $1-S_{c}$. The proportion shot elsewhere is $\left(1-S_{e}\right) S_{c}$, because those birds must first survive hunting on the Forest. Thus, the percentage of kill on the Forest can be expressed as

$$
\begin{aligned}
\phi & =\frac{1-S_{c}}{1-S_{c}+\left(1-S_{e}\right) S_{c}} \\
& =\left(1-S_{c}\right) /\left(1-S_{c} S_{e}\right)=0.548
\end{aligned}
$$

and

$$
\phi^{\prime}=\left(1-S_{c}{ }^{\prime}\right) /\left(1-S_{c}{ }^{\prime} S_{e}{ }^{\prime}\right)=0.424 .
$$

It is now possible to solve for $S_{c}, S_{e}, S_{c}{ }^{\prime}$, and $S_{e}{ }^{\prime}$ to obtain the following:

$$
\begin{aligned}
S_{c} & =0.896 \\
S_{e} & =0.905 \\
S_{c}{ }^{\prime} & =0.897 \\
S_{e}{ }^{\prime} & =0.843 .
\end{aligned}
$$

Notice the harvest rates on the Forest are essentially identical for adults and young. From equation A3, we have

$$
S_{c}=(1-\phi) /\left(1-\phi S_{e}\right)
$$

which we can use in equation 3 to write the population change $C$ as a function of the proportion of birds taken on the Forest:

$$
\begin{gathered}
C=\left(S_{b} S_{e} S_{w}+R S_{e}{ }^{\prime} S_{w}{ }^{\prime}\right) \\
\cdot(1-\phi) /\left(1-\phi S_{e}\right) .
\end{gathered}
$$

This function is plotted for various values of $R$ in Fig. 6.

\section{APPENDIX 3. PARAMETERS SPECIFIC TO THE EASTERN NORTH DAKOTA EXAMPLE}

We modeled the annual change in the mallard population as a function of the proportion of breeding hens nesting in treated cover. We examined this relationship for various levels of survival from hunting harvest, a parameter of great interest to the manager.

Let $\theta$ equal the proportion of hens nesting in dense nesting cover. Then, from Table 3 , the hatch rate $(P)$ will vary according to $\theta$; viz.

$$
\begin{aligned}
P(\theta) & =(1-\theta)(0.14)+\theta(0.21) \\
& =0.14+0.07 \theta .
\end{aligned}
$$

In order to estimate $S_{b}$ for the various situations, we assumed that $S_{b}$ and $P$ both vary primarily because of predation. In areas subject to normal predation $S_{b}$ is about 0.72 (Johnson and Sargeant 1977) and $P$ is about 0.14 (Table 3 ). We assumed that in the absence of predation $S_{b}$ would be about 0.95 , which allows a $5 \%$ loss to causes other than predation, and $P$ would be 1.0 . Fitting a straight line to these pairs of points we obtain the following relationship between $S_{b}$ and $P$ :

$$
S_{b}=0.682+0.267 P \text {. }
$$

We also required estimates of $S_{w}$ and an estimate of $S$ for managed areas in North Dakota. These estimates were obtained by using $S_{b}$ estimated from equa- 
tion A5 and estimates of survival from hunting kill $\left(S_{h}\right)$ obtained from Anderson (1975a), corrected for an 18\% crippling loss (Johnson and Sargeant 1977). Solving for $S_{w}$ in equation 2 , we obtained $S_{w}=$ 0.918 . In the examples of managed cover in the Dakotas the treatment would increase $S_{b}$, but we assumed that $S_{w}$ and $S_{h}$ would be the same as in populations from unmanaged areas.

Our composite equation 7 may now be written

$$
\begin{aligned}
C & =0.918 S_{h} S_{b}\left(1+1 / 2 D P \mathrm{e}^{(1-P)^{2}} Z B / S_{b}\right) \\
& =0.918 S_{h}\left(S_{b}+1 / 2 D Z B P \mathrm{e}^{(1-P)^{2}}\right),
\end{aligned}
$$

and if we use the estimates as given earlier,

$1 / 2 D Z B=(0.5)(0.945)(0.70)(4.9)=1.6207$.

Therefore,

$$
C=0.918 S_{h}\left(S_{b}+1.6207 P \mathrm{e}^{(1-P)^{2}}\right) .
$$

If we use equation A6 with $P$ as a function of $\theta$ (equation A4) and $S_{b}$ as a function of $P$ (equation A5), we can construct a graph relating the change in population $(C)$ to the proportion of hens nesting in the treated area $(\theta)$ and for various levels of survival from harvest $\left(S_{h}\right)$. These rela- tionships are graphed in Fig. 7 for the DNC treatment.

A similar approach may be used for examining the relationship between annual change in population and the proportion of hens nesting in DNC with predator control as an additional treatment. For this combination, the nest success rate is

$$
\begin{aligned}
P(\theta) & =(1-\theta)(0.14)+\theta(0.87) \\
& =0.14+0.73 \theta .
\end{aligned}
$$

Predator control not only influences $P$ but also undoubtedly increases $B, Z$, and $S_{b}$. Lacking any data about the effect of predator control on these parameters, we simply assumed that mortality of ducklings and loss of total broods would be half that observed under normal predation. Under this assumption $B=6.44$ and $Z=0.85$. If we again assume a straight line relationship, we get

$$
B=4.90+1.54 \theta
$$

and

$$
Z=0.70+0.15 \theta .
$$

Equation A6 with these relationships is plotted in Fig. 8 for various levels of survival from hunting.

Received 5 October 1977.

Accepted 7 August 1978. 